\title{
JUDICIALIZAÇÃO DO DIREITO À SAÚDE EM DESFA VOR DOS MUNICÍPIOS: UM PARADOXO AOS PRINCÍPIOS DA ISONOMIA E DA RESERVA DO POSSÍVEL
}

\author{
JUDICIALIZATION OF THE RIGHT TO HEALTH TO THE DISADVANTAGE OF \\ MUNICIPALITIES: A PARADOX TO THE PRINCIPLES OF EQUAL TREATMENT AND \\ OF THE RESERVATION OF THE POSSIBLE
}

\begin{abstract}
Mestre em Direito com a linha de pesquisa Empreendimentos Econômicos, Processualidade e Relações Jurídicas pela Universidade de Marília - UNIMAR (2016). Especialista em Direito Material e Processual do Trabalho pelo Centro Universitário de Rio Preto - UNIRP (2015). Graduada em Direito pela Universidade do Estado de Minas Gerais - UEMG, campus de Frutal/MG (2010). E-mail:gabrielaeulalio.adv@ hotmail.com
\end{abstract}

Aflaton Castanheira Maluf

Graduação em Direito pela Associação de Ensino Superior da Amazônia-AESA-FARO,

Especialista em Direito do Estado pela UNIUBE / MG e Direito Ambiental pelo IED /

MG, Mestre em Direito do Estado pela Universidade de Franca - UNIFRAN / SP e Doutor em Função Social no Direito Constitucional pela FADISP / SP. Experiência nas áreas de Direito Público e Privado, principalmente: Civil, Processo e Arbitragem, Notarial e Registral, Agrário, Ambiental, Municipal e Constitucional.E-mail:aflaton33@gmail.com

Recebido em: 20/04/2017

Aprovado em: 05/12/2017

RESUMO: O presente trabalho teve por escopo discorrer sobre a importância do direito à saúde como um dever estatal e um direito de acesso a todos, resguardado pela Constituição da República Federativa do Brasil de 1988, mas que tem tido sua função primordial deturpada face ao fenômeno da sua judicialização, especialmente por não haver por parte do poder judiciário a observância necessária, quando da prolação de decisões em demandas desta natureza - genéricas e lacônicas, quanto à divisão do grau de responsabilidade de cada Ente federado, bem como a competência para prestar tal garantia do fármaco e/ou procedimento médico demandado, dando azo a uma incoerência protetiva sobremaneira para os municípios, mormente em relação aos princípios da isonomia e da reserva do possível, atingindo os efeitos da decisão apenas um particular - o demandante, olvidando-se igualmente os limites orçamentários da administração pública municipal. Para tanto, utilizou-se o método dedutivo, esquadrinhando-se da pesquisa bibliográfica e documental para a apreensão do contexto teórico na forma estruturada e organizada no trabalho.

Palavras-chave: Direito à saúde; Judicialização; Isonomia e reserva do possível.

ABSTRACT: The present study had the scope to talk about the importance of the right to health as a state has a duty and a right of access for all, enshrined by the Constitution of the Federative Republic of Brazil of 1988, but which has had its primary function mangled face to the 
phenomenon of your judicialization, especially because there on the part of the judiciary, the observance required, when the passing of decisions in the demands of this nature - general and laconic, as far as the division of the degree of responsibility of each federal Entity, as well as the competence to provide such guarantee of the drug and/or medical procedure by a defendant, giving rise to an incoherence protective measure for the municipalities, especially in relation to the principles of equal treatment and of the reservation of the possible, reaching the effects of the decision only an individual - the applicant, forgetting-also the budgetary limits of public administration hall. For both, we used the deductive method, scanning of the literature search and documentary for the seizure of the theoretical context in a structured and organised at work.

Keywords: Right to health; Judicialization; Equality and reservation possible.

SUMÁRIO: Introdução; 1 A saúde como um direito de todos e um dever estatal; 1.1 A Saúde nas constituições estrangeiras; 1.2 A saúde no ordenamento jurídico brasileiro; 2 Resultados oriundos da judicialização do direito à saúde; $3 \mathrm{O}$ direito à saúde e os princípios jurídicos da isonomia e da reserva do possível; 3.1 Princípio da igualdade; 3.2 Princípio da reserva do possível; Considerações Finais; Referências

\section{INTRODUÇÃO}

A temática que será abordada no presente artigo, trata-se de discussão trivial que vem se multiplicando nos tribunais de justiça brasileiros, estar-se falando do direito à saúde e o avanço do fenômeno da sua judicialização. (SÃ̃ PAULO, 2016, n.p.)

Uma vez disposto na Constituição da República de 1988, como um direito de acesso a todos(artigo 196), a saúde também compreende um direito social (artigo $6^{\circ}$ ) e uma obrigação estatal, sendo competência comum dos Entes da federação brasileira (União - Estados - DF Municípios) promove-la em prol das pessoas que dela necessitarem (artigo 23, inciso II).

A saúde deve ser garantida por meio de políticas sociais e econômicas na intenção de reduzir o risco de doença e de outros agravos, condicionando o acesso universal e igualitário às ações e serviços para a promoção, proteção e recuperação, o direito à saúde tem sido cada vez mais objeto de discussões judiciais.

Ocorre que, os litígios discutindo esta matéria, na grande maioria das vezes estão sendo instaurados em desfavor de apenas um dos Entes da federação - os Munícipios - e é neste ponto, que desponta o grande entrave de conflitos de direitos igualmente previstos na Carta Constitucional, fruto de decisões superficiais e genéricas do Poder Judiciário, que dão azo a uma incoerência protetiva principalmente em relação aos princípios da isonomia e da reserva do possível.

A regra estatuída no artigo 196 do Texto Constitucional possui caráter programático, cujos obrigados devem ser compreendidos todos os Entes da organização federativa do território nacional. Portanto, sabendo-se que o direito à saúde cuida de um preceito constitucional que não pode ser abalizado somente em meras expectativas e/ou promessas institucionais, não merece, por outro lado, pesar a responsabilidade apenas ou imediatamente em detrimento dos Entes municipais - isso para as ações em que os Municípios são processados em litisconsórcio passivo com outro (s) ente (s) público (estados membros e/ou União), mas que por serem intimados de forma mais imediata das decisões judiciais que deferiram os pedidos de tutela, têm por consequência a obrigação de cumprimento da ordem judicial a partir de então - sob pena de impulsionar o agravamento das desigualdades no acesso à atenção a saúde dos demais munícipes, gerando mais iniquidades sociais.

Neste sentido, essa pesquisa objetivará elucidar os problemas ocasionados pelo fenômeno da judicialização do direito à saúde, enfatizando principalmente os impactos suportados pelos Entes municipais, traçando uma interconexão entre o direito universal à saúde e 
o dever estatal em prestá-lo com a ressalva da incongruência provocada pelas decisões judiciais lacônicas e genéricas em relação aos princípios da isonomia e da reserva do possível, que dá como resultado a ineficiência da garantia do direito constitucional à saúde decorrente dos riscos suscitados a própria ordem constitucional.

Essa investigação será estruturada com base no método dedutivo de pesquisa, a fim de refletir a realidade fática como o direito à saúde vem sendo abalizado através do fenômeno da sua judicialização, demonstrando a incoerência com a intenção do constituinte, partindo da demonstração de pesquisa bibliográfica e documental.

\section{A SAÚDE COMO UM DIREITO DE TODOS E UM DEVER ESTATAL}

A palavra saúde possui vários significados, sendo recorrente em vários ramos do conhecimento. Em primeiro, temos o verbete "saúde" nos dicionários da língua nacional. Definea HOUAISS:

1. Estado de equilíbrio dinâmico entre o organismo e seu ambiente, o qual mantém as características estruturais e funcionais do organismo dentro dos limites normais para a forma particular de vida (raça, gênero, espécie) e para a fase particular de seu ciclo vital (o check up comprovou que tem s. perfeita) 2 . Estado de boa disposição física e psíquica; bem estar (apesar da idade, apresenta ótima s.) [...] s. pública MED especialidade médica que se dedica ao estudo de doenças que perturbam gravemente a vida social (p. ex. doenças contagiosas e epidêmicas, toxicomaníacas, doença mental etc.) e ao estabelecimento de ações e prescrições referentes a preservação e proteção da saúde dos cidadãos, em escala nacional, ou mesmo em escala mundial. [...] (HOUAISS, 2001, p. $2525 / 2526)$

As profissões ligadas diretamente ao tema da saúde humana (Medicina, Enfermagem, Fisioterapia, Odontologia, Fonoaudiologia, Psicologia, Biomedicina etc.), possuem visão ampla sobre a questão. Para tais profissões, "saúde" não deve ser compreendida apenas como ausência de doença ou enfermidade, devendo ser analisada como um estado de total bem-estar físico, mental e social. Essa, aliás, é a visão adotada pela World Health Organization - OMS. (OMS, 2017, n.p.) Daí torna-se fácil inferir, inicialmente, que existem várias espécies e subespécies dentro do gênero "saúde".

No plano internacional, além da OMS, temos vários organismos e instrumentos, bem como publicações dedicadas a essa temática, incluindo questões interdisciplinares. Impende colacionar aqui, a título de exemplo, o Diccionario Latinoamericano de Bioética:

La Declaración Americana de los Derechos y Deberes del Hombre, instrumento regional aprobado por la Novena Conferencia Internacional Americana celebrada en Bogotá del 30 de marzo al 2 de mayo de 1948, antecedió a la Declaración Universal de los Derechos Humanos, que sería adoptada por la Asamblea General de las Naciones Unidas el 10 de diciembre de ese mismo año. La contribución regional a esta última fue relevante. En su artículo 11, la Declaración Americana asocia el derecho a la preservación de la salud con el derecho al bienestar cuando establece que "toda persona tiene derecho a que su salud sea preservada por medidas sanitarias y sociales, relativas a la alimentación, el vestido, la vivienda y la asistencia médica, correspondientes al 
nivel que permitan los recursos públicos y los de la comunidad"I(UNESCO, 2008, p. 66)

Historicamente, a saúde passou a ser redefinida a partir do século $\mathrm{XX}$, onde se deu grande crescimento populacional mundial, proporcionado - dentre outros fatores - pelo surgimento de novas tecnologias, a título de exemplos: descobrimento de fármacos e novos procedimentos preventivos e/ou invasivos (cirurgias, por ex.). Com esses avanços nas ciências da saúde, emergiram a diminuição da mortalidade e o prolongamento da vida. O conceito de "saúde" além de multidisciplinar deve ter dimensão aberta. Nesse sentido:

O conceito de assistência à saúde, entendido ainda por alguns como sinônimo de prática médica curativa ou preventiva, ou como simples organização dos serviços prestados em atendimento, não pode ser mais aceito. Mas como um conjunto de políticas sociais complementares que não passa exclusivamente pela prática assistencial. O conceito moderno de saúde transcende uma dimensão política, fruto de uma composição dos níveis e das condições de vida que vai além da organização sanitária. [...] A saúde e as liberdades individuais representam, num estado democrático de direito, os bens mais fundamentais. (FRANÇA, 2010, p. 93)

Ultrapassada este momento da definição do conceito de saúde, passa o trabalho a expor o tratamento do referido direito nas constituições estrangeiras.

\subsection{A SAÚDE NAS CONSTITUIÇÕES ESTRANGEIRAS}

No plano constitucional comparado, as Constituições estrangeiras, notadamente as da iberoamérica dedicaram atenção especial à saúde. Algumas constituições são originalmente do séc. XIX (a do México, tornou-se centenária), mas passaram por amplas reformas e ampliações em seus textos. São exemplos: Argentina 1853 (artigo 42); Bolívia 2009 (artigos 18,35); Colômbia 1991 (artigo 49); Cuba 1976 (artigo 50); Chile 1980 (artigo 19.9); Equador 2008 (artigos 358/366); El Salvador 1983 (artigo 1,65); Espanha 1978 (artigo 43); Guatemala 1985 (artigos 93 y ss.); Honduras 1982 (artigos 145-150); México 1917 (artigo 4); Nicarágua 1986 (artigos 59, 105); Panamá 2004 (artigos 109 y ss.); Paraguai 1992 (artigos 68-72); Peru 1993 (artigo 9); Portugal 1976 (artigo 64); Porto Rico 1952 (artigo 2.20); República Dominicana 1844 (artigo 8.17); Uruguai 1967 (artigo 44); Venezuela 2009 (artigos 83 y ss. 156.24), etc.

Nessa senda, torna-se relevante citar expressamente o dispositivo da Constituição Espanhola de 1978:

Artículo. 43.

1. Se reconoce el derecho a la protección de la salud.

2. Compete a los poderes públicos organizar y tutelar la salud pública a través de medidas preventivas y de las prestaciones yservicios necesarios. La ley establecerá los derechos y deberes de todos al respecto.

\footnotetext{
${ }^{1}$ Tradução livre: A Declaração Americana dos Direitos e Deveres do Homem, instrumento regional aprovado pela Nona Conferência Internacional realizada em Bogotá de 30 de março a 2 de maio de 1948, ele precedeu a Declaração Universal dos Direitos Humanos, a ser adoptada pela Assembleia geral das Nações Unidas em 10 de dezembro do mesmo ano. A contribuição regional para o último foi relevante. $\mathrm{O}$ artigo 11 da Declaração Americana associa o direito à preservação da saúde com o direito ao bem-estar quando afirma que "todos têm o direito à saúde é preservada por medidas sanitárias e sociais relativas à alimentação, vestuário, habitação e saúde, assistência adequada, na medida permitida recursos públicos e da comunidade".
} 
3. Los poderes públicos fomentarán la educación sanitaria, la educación física y el deporte. Asimismo facilitarán la adecuada utilización del ocio. ${ }^{2}$ (GUERRA; LUQUE, 2009, p. 1090)

E da Constituição Portuguesa de 1976:

ARTIGO 64. ${ }^{\circ}$ (Saúde) 1. Todos têm direito à protecção [sic.] da saúde e o dever de a defender e promover. 2. O direito à protecção [sic.] da saúde é realizado pela criação de um serviço nacional de saúde universal, geral e gratuito, pela criação de condições económicas, sociais e culturais que garantam a protecção [sic.] da infância, da juventude e da velhice e pela melhoria sistemática das condições de vida e de trabalho, bem como pela promoção da cultura física e desportiva, escolar e popular e ainda pelo desenvolvimento da educação sanitária do povo. 3. Para assegurar o direito à protecção [sic.] da saúde, incumbe prioritariamente ao Estado: a) Garantir o acesso de todos os cidadãos, independentemente da sua condição económica, aos cuidados da medicina preventiva, curativa e de reabilitação; b) Garantir uma racional e eficiente cobertura médica e hospitalar de todo o pais; c) Orientar a sua acção [sic.] para a socialização da medicina e dos sectores médico-medicamentosos; d) Disciplinar e controlar as formas empresariais e privadas da medicina, articulando-as com o serviço nacional de saúde; e) Disciplinar e controlar a produção, a comercialização e o uso dos produtos químicos, biológicos e farmacêuticos e outros meios de tratamento e diagnóstico. (GUERRA; LUQUE, 2009, p. $1853 / 1854)$

Infere-se de plano, semelhança do texto constitucional português (de 1976) com o atual brasileiro (de 1988). Os próceres do direito constitucional brasileiro afirmam - com razão - que os textos constitucionais da Espanha (1978) e Portugal (1976) serviram de norte, exercendo clara influência na atual Carta brasileira, promulgada pela Assembleia Nacional Constituinte de 19871988.

A saúde, portanto, compreende legítimo direito fundamental. Nesse aspecto, as políticas públicas nacionais e como destacado também as estrangeiras, dedicam especial atenção a sua justa efetivação. É certo que um dos indicadores de desenvolvimento de um país está na saúde efetivamente proporcionada. Sendo mais otimizada e equânime as políticas públicas do sistema de saúde, em corolário, mais eficaz será o desenvolvimento econômico e social da respectiva nação.

\subsection{A SAÚDE NO ORDENAMENTO JURÍDICO BRASILEIRO}

Garantida na atual Carta da República de 1988 como um direito social ${ }^{3}$ de todos e dever do Estado ${ }^{4}$, a saúde ganhou status de direito público subjetivo, ao passo que encontra-se constitucionalmente tutelada. Ao poder público, para tanto, o constituinte instaurou a obrigação

\footnotetext{
${ }^{2}$ Tradução livre: Artigo. 43.

1. O direito à proteção da saúde.

2. Compete aos poderes públicos organizar e salvaguardar a saúde pública através de medidas preventivas e os benefícios e serviços necessários. A lei estabelece os direitos e deveres de todos a este respeito.

3. As autoridades públicas devem promover a educação para a saúde, a educação física e do desporto. Eles também incentivar o uso adequado de lazer.

${ }^{3}$ Art. $6^{\circ}$. São direitos sociais a educação, a saúde, a moradia, o lazer, a segurança, a previdência social, a proteção a maternidade e a infância, a assistência aos desamparados, na forma desta Constituição.

${ }^{4}$ Art. 196. A saúde é direito de todos e dever do Estado, garantido mediante políticas sociais e econômicas que visem à redução do risco de doença e de outros agravos e ao acesso universal e igualitário às ações e serviços para sua promoção, proteção e recuperação.
} 
de ordenar políticas sociais e econômicas dedicadas aos cidadãos que viabilize o acesso universal à saúde.

Contudo, releva-se ressaltar outros aspectos constitucionais que se referem à competência dessa responsabilidade estatal, que é dividida de "forma horizontal".Essa competência horizontal no Texto Constitucional é denominada"comum" entre todos os Entes da federação: União, Estados membros, Distrito Federal e Municípios, cabendo a cada qual, no limite do domínio administrativo, o dever de cuidado com a saúde e a assistência pública a população. ${ }^{5}$

Não obstante o entendimento do constituinte, a legislação especial, precisamente através da Lei Federal n. ${ }^{\circ}$ 8.080/1990 (SUS - Sistema Único de Saúde), ratificou como sendo comuns as atribuições da União, dos Estados membros, do Distrito Federal e dos Municípios, o exercício no âmbito administrativo da definição das instâncias e mecanismos de controle, avaliação e de fiscalização das ações e serviços de saúde. ${ }^{6}$

Percebe-se assim, tratar-se de um dever que necessita ser analisado e ponderado dentro dos limites de cada Ente da federação, de modo a não ser cabível pesar a guarda e proteção deste direito em desfavor daquele que não esteja legalmente incumbido de prestar a assistência como previamente estabelecido pelas regras de competência para a garantia.

Esta responsabilidade estatal, em tese, está revestida de caráter público e, portanto, significa aquele acesso universal e gratuito à saúde, que no Brasil desde 1988, com a promulgação da Constituição da República em vigência, é coberto pelo SUS - Sistema Único de Saúde $^{7}$ - que embora seja considerado ineficaz pelos seus usuários, é considerado um dos maiores sistemas públicos de saúde do mundo, com cobertura desde simples atendimentos ambulatoriais até intervenções cirúrgicas com transplantes de órgãos. (BRASIL. Entenda o SUS, n.p.)

Acontece que além de direito social, como expressamente garantido nos termos constitucionais, ${ }^{8}$ a saúde também esbarra diretamente no direito à vida, consagrado pelo constituinte como um direito fundamental, ${ }^{9}$ tendo em vista que sem a estabilidade e/ou os

\footnotetext{
${ }^{5}$ Art. 23. É competência comum da União, dos Estados, do Distrito Federal e dos Municípios:

$[\ldots]$

II - cuidar da saúde e assistência pública, da proteção e garantia das pessoas portadoras de deficiência;

$[\ldots]$

${ }^{6}$ Art. 15. A União, os Estados, o Distrito Federal e os Municípios exercerão, em seu âmbito administrativo, as seguintes atribuiç̧ões:

I - definição das instâncias e mecanismos de controle, avaliação e de fiscalização das ações e serviços de saúde;

$[\ldots]$

${ }^{7}$ Art. 200. Ao sistema único de saúde compete, além de outras atribuições, nos termos da lei:

I - controlar e fiscalizar procedimentos, produtos e substâncias de interesse para a saúde e participar da produção de medicamentos, equipamentos, imunobiológicos, hemoderivados e outros insumos;

II - executar as ações de vigilância sanitária e epidemiológica, bem como as de saúde do trabalhador;

III - ordenar a formação de recursos humanos na área de saúde;

IV - participar da formulação da política e da execução das ações de saneamento básico;

V - incrementar, em sua área de atuação, o desenvolvimento científico e tecnológico e a inovação;

VI - fiscalizar e inspecionar alimentos, compreendido o controle de seu teor nutricional, bem como bebidas e águas para consumo humano;

VII - participar do controle e fiscalização da produção, transporte, guarda e utilização de substâncias e produtos psicoativos, tóxicos e radioativos;

VIII - colaborar na proteção do meio ambiente, nele compreendido o do trabalho.

${ }^{8}$ Art. $6^{\circ}$ São direitos sociais a educação, a saúde, a alimentação, o trabalho, a moradia, o transporte, o lazer, a segurança, a previdência social, a proteção à maternidade e à infância, a assistência aos desamparados, na forma desta Constituição.

${ }^{9}$ Art. $5^{\circ}$ Todos são iguais perante a lei, sem distinção de qualquer natureza, garantindo-se aos brasileiros e aos estrangeiros residentes no País a inviolabilidade do direito à vida, à liberdade, à igualdade, à segurança e à propriedade, nos termos seguintes:
}

Revista de Direito Brasileira | São Paulo, SP | v. 20 | n. 8 | p. 174-191 |Mai./Ago. 2018 
cuidados necessários com a saúde do cidadão, este se encontra totalmente vulnerável a riscos de morte.

Por tal razão, somada a insuficiência de recursos na área da saúde e a conscientização cada vez mais ampla dos indivíduos quanto à abrangência dos seus direitos, estes têm buscado em escala aritmeticamente astronômica a tutela jurisdicional para socorrerem o que entendem de direito, por meio de propositura de demandas judiciais, que variam desde pedidos para o fornecimento simples de remédios de médio e alto custo, realização de exames, procedimentos cirúrgicos, entre outros tratamentos que muitas vezes estão baseados em evidências científicas pobres, que não levam em consideração a relação custo-efetividade e/ou as prioridades da saúde pública.

Estar-se diante do fenômeno da judicialização da saúde, que embora tenha o condão de garantir aos cidadãos o acesso ao seu direito constitucional, tem produzido uma enorme distorção no campo prático social.

A mudança de rumos na condução de formulação de políticas públicas para o Poder Judiciário, obrigando o Poder Executivo a atender as pretensões dos litigantes - com grande parte das decisões indicando aplicação de astrientes para o descumprimento da ordem judicial - sem tratar o direito à saúde de maneira adequada, respeitando, portanto, os limites legais quanto à cobertura do SUS e a competência de cada ente estatal no dever de garantia - têm gerado sérios prejuízos, não só aos cidadãos como ao próprio Estado, isso considerando que as decisões podem atingir tanto pedidos que não tenham a cobertura do Sistema Único de Saúde, como pode ser demandado contra Ente público que não tenha a obrigação direta de garantir a prestação da tutela suscitada em juízo.

No tocante a responsabilidade dos Municípios, o protagonismo do Poder Judiciário no acesso ao direito à saúde, tem ignorado previsão fundada no Texto Constitucional - inciso VII do artigo 30 - quando releva que compete aos Entes municipais prestar, com a colaboração procedimental e financeira da União e do Estado, serviços de atendimento a saúde da população; e por tal razão, as decisões judiciaispodem ser consideradas oportunamente inconstitucionais.

Bom ressaltar que a defesa aqui não é anular o direito fundamental do cidadão petrificado no inciso XXXV do artigo $5^{\circ}$ da Carta Maior - o amplo acesso ao Poder Judiciário, firmando um entendimento pela inafastabilidade da jurisdição, chama-se apenas a atenção para o ativismo judicial, que contrariamente ao que vem sendo desenvolvido - com a manifestação de decisões idênticas, alterando apenas os números de processos e nomes das partes - deveria idealizar o direito reivindicado, pautado numa gama de fundamentos mais criteriosos, referindose aos limites previstos nas políticas públicas disponíveis para cada Ente da federação, relevandose, portanto, a responsabilidade específica pertinente à área da saúde para cada qual, em respeito as características estruturais e orçamentárias deles.

Destarte, o que se tem percebido é que a análise do Poder Judiciário perante um caso prático envolvendo pedidos relacionados ao direito à saúde, diversa do que exige a própria semântica do termo "direito" (complexo por sua natureza), tem revelado um julgamento simples em demasia, sendo empregado um sentido valorativo sinônimo ao de justiça.

APELAÇÃO CÍVEL. CONSTITUCIONAL. DIREITO FUNDAMENTAL À SAÚDE - CF, arts. $6^{\circ}$ e 196 -. FORNECIMENTO DE MEDICAMENTO. LEGITIMIDADE PASSIVA DO MUNICÍPIO DE MACEIÓ. PRELIMINAR DE DENUNCIAÇÃO DA LIDE AO ESTADO DE ALAGOAS E À UNIÃO, POR TRATAR-SE DE OBRIGAÇÃO SOLIDÁRIA ENTRE OS ENTES DA FEDERAÇÃO, REJEITADA. JUDICIALIZAÇÃO DO DIREITO À SAÚDE. RESERVA DO POSSÍVEL. DIGNIDADE DA PESSOA HUMANA E O MÍNIMO EXISTENCIAL - CF, art. $1^{\circ}$, inciso III. HONORÁRIOS ADVOCATÍCIOS DEVIDOS À DEFENSORIA PÚBLICA ESTADUAL PELO MUNICÍPIO. MAJORAÇÃO. POSSIBILIDADE. DOUTRINA E 
JURISPRUDÊNCIA. I. Diversamente do que alega e sustenta o Município de Maceió, no que diz respeito à questão da denunciação da lide ao Estado de Alagoas e à União, sob a ótica jurisprudencial do Supremo Tribunal Federal e do Superior Tribunal de Justiça, há de prevalecer a responsabilidade solidária dos entes públicos federativos = da União, dos Estados, dos Municípios e do Distrito Federal -, relativamente à garantia do direito à saúde, de modo que tanto faz a parte demandar contra um ou o outro, de forma conjunta ou isolada, sendo inoportuno o chamamento dos demais entes federativos, no caso, já que demandaria uma mobilização desnecessária da máquina judiciária, de caráter eminentemente procrastinatório. II. É inquestionável - sem sombra de dúvida que, no caso dos autos, tratando-se de direito público subjetivo à saúde - $\mathrm{CF}$, arts. $6^{\circ}$ e 196 , sob a provada repercussão da chancela do mínimo existencial, enquanto direito social fundamental - $\mathrm{CF}$, art. $6^{\circ}$, que tem substrato no princípio da dignidade da pessoa humana - $\mathrm{CF}$, art. $1^{\circ}$, inciso III, é dever do Município de Maceió adotar as medidas necessárias com vista a garantir ao Autor o pretendido medicamento descrito na petição inicial. III. Contrariamente ao que ressalta o Município de Maceió, aqui apelante = recorrente, não se trata de interferência anômala, mas de efetiva e constitucionalmente legítima intervenção do Poder Judiciário no sentido de suprir omissão do próprio Poder Público, relativamente ao direito fundamental à saúde $\mathrm{CF}$, arts. $6^{\circ}$ e 196 , sob os auspícios dos princípios da separação dos poderes, da inafastabilidade da jurisdição e da moralidade administrativa e como medida de justiça ex vi da $\mathrm{CF}$, arts. $2^{\circ}, 5^{\circ}$, inciso XXXV, e 37. IV. [...] (TJAL, 2014, APL: 00621685820108020001)

Miguel Reale evidencia que deve-se observar a regra de direito vista de dentro, como uma ação regulada. (REALE, 1995, p. 63) Hans Kelsen, avalia a partir do exame linguístico, que a acepção da palavra recht $^{10}$ e suas terminologias em outros idiomas, diz respeito à ordens de conduta humana, arrematando tratar-se de uma ordem e um sistema de normas cuja integração é composta do resultado de todas elas apresentarem o mesmo fundamento de validade. (KELSEN, 1998, p. 21)

Dedicadamente sobre as discussões pautadas no direito à saúde, observa-se que o termo "direito" é empregado e abrigado nas demandas judiciais em sentido subjetivo, enquanto que a regra da sua aplicação - visando a eficácia proposta pelo constituinte -necessariamente, deveria implicar na sua abrangência como regra social para toda a coletividade.

AGRAVO DE INSTRUMENTO. DIREITO PÚBLICO NÃO ESPECIFICADO. SAÚDE PÚBLICA. MICROCIRURGIA DE LARINGE COM LASER. FORNECIMENTO, CUSTEIO PELO MUNICÍPIO. POSSIBILIDADE. LIMINAR DEFERIDA. A Carta Magna erigiu a saúde como sendo direito de todos e dever do Estado, nos termos dos arts. 196, da CF e 241, da CE, portanto, inconteste a obrigação do Estado, independentemente de qual seja a esfera de poder, em virtude da competência comum, conforme o disposto no art. 23, II, da CF. Comprovada a necessidade do indivíduo ao tratamento e a sua carência econômica para financiá-lo, é dever do ente público o fornecimento. [...] AGRAVO DE INSTRUMENTO DESPROVIDO. UNÂNIME. (TJRS, 2013, AI: 70052460383)

Diferentemente de como vem sendo evidenciada pela maioria dos operadores do Direito em suas decisões, uma vez definida como um direito, a saúde carece ter observados seus aspectos sociais e individuais e como um direito subjetivo, ficando condicionada ao grau de

${ }^{10}$ Direito em alemão.

Revista de Direito Brasileira | São Paulo, SP | v. 20 | n. 8 | p. 174-191 |Mai./Ago. 2018 
desenvolvimento estatal. Analisada, por outro lado, como direito coletivo - no campo social, a saúde necessita privilegiar a igualdade. (SILVA, 2015, p. 13)

Veja-se que a defesa não é negar o direito à saúde ou o dever estatal na sua prestação, contudo, é necessário que sejam adotadas algumas cautelas e/ou critérios para o manejo dos mecanismos processuais que viabilizam a intervenção jurisdicional na efetivação da assistência a saúde pelo Poder Público, a fim de se desenvolver esse direito fundamental dentro de um equilíbrio equitativo de valores - campo da liberdade individual e da igualdade social.

Deste modo, considerando a divisão do Estado brasileiro em Entes da federação, o fato é que muitas são as regras constitucionais que tratam transversalmente do direito à saúde, contudo carece atentar para o grau de responsabilidade de cada Ente, observando-se que os Municípios são os que possuem a parcela de recursos financeiros mais parca; o financiamento recebido do SUS é insuficiente e não é capaz de atender a grande demanda da sociedade. Logo, ao serem compelidos a dispensarem recursos para atenderem decisões judiciais alcançando uma pessoa de forma isolada, é certo que direitos e garantias fundamentais da coletividade - dos demais munícipes - estarão em risco premente de serem feridos.

\section{RESULTADOS ORIUNDOS DA JUDICIALIZAÇÃO DO DIREITO À SAÚDE}

Verificadas as questões atinentes a saúde como um direito de todos e um dever estatal, passa agora a destacar os maiores impactos sofridos pelos Municípios, oriundos da judicialização do direito em discussão.

Como ressaltado anteriormente, a saúde é consagrada pela Constituição da República como um direito de todos - artigo 196; para regular tal dispositivo, para tanto, veio a lume a Lei Federal n. ${ }^{\circ}$ 8.080/1990, que em sua rubrica deixa claro seu intuito: "Dispõe sobre as condições para a promoção, proteção e recuperação da saúde, a organização e o funcionamento dos serviços correspondentes e dá outras providências." (BRASIL, Lei n. ${ }^{\circ} 8.080$, de 19 de setembro de 1990).

Contudo, é imprescindível notar que a legislação mencionada demandava de um decreto para a sua execução concreta, o que se deu através do Decreto n. ${ }^{\circ}$ 7.508, de 28 de junho de 2011; referido, regulamenta a lei federal, retro mencionada, para dispor sobre a organização do Sistema Único de Saúde - SUS, o planejamento da saúde, a assistência à saúde e a articulação interfederativa. (BRASIL, Decreto n. ${ }^{\circ}$ 7.508, de 28 de junho de 2011)

Mais precisamente, com a redação do artigo 27 do Decreto Federal em alusão, é possível verificar a disposição que possibilita o Estado, o Distrito Federal e os Municípios adotarem relações específicas e complementares de medicamentos, em harmonia com a RENAME Relação Nacional de Medicamentos Essenciais, respeitadas os encargos dos Entes pelo financiamento de medicamentos, de acordo com o pactuado nas Comissões Intergestores.

Diante desse contexto, na análise da responsabilidade pela aquisição e fornecimento de tais medicamentos impõe trazer à baila a Portaria n. ${ }^{\circ} 2.982$ de 26 de novembro de 2009, que "Aprova as normas de execução e de financiamento da Assistência Farmacêutica na Atenção Básica.", que funciona com base numa pactuação de Intergestores Tripartite. (BRASIL, Portaria no 2.982 de 26 de novembro de 2009)

Nesse sentido, caberia ao particular o direito de reclamar dos Municípiosapenas aqueles medicamentos incluídos na sua esfera de atribuição e reclamar dos Estados membrose da União os fármacosque lhes compete, assim definidos através de normas expedidas pelo SUS e Ministério da Saúde.

Contudo, o que se tem percebido das decisões prolatadas em ações envolvendo o direito à saúde, é que grande parte delas, não agrega valor as demais normas que regulamentam o direito em discussão e com base irrestrita no artigo 196 da Constituição da República, decreta-o como direito líquido, certo e absoluto, impulsionando a esperança e a confiança do particular no fenômeno da judicialização de ter o direito à saúde atendido a qualquer custo pelas vias judiciais. 
REEXAME NECESSÁRIO. NECESSIDADE DO PACIENTE SE SUBMETER A SESSÕES DE OXIGENORAPIA HIPERBÁRICA. SENTENÇA DE PROCEDÊNCIA DO PEDIDO, CONFIRMANDO A ANTECIPAÇÃO DE TUTELA. RECURSO DO MUNCÍPIO ALEGANDO JUDICIALIZAÇÃO DO DIREITO A SAÚDE, PRINCÍPIO DA SEPARAÇÃO DOS PODERES E RESERVA DO POSSÍVEL. ART. 196 DA CF. DIREITO À VIDA E À SAÚDE. GARANTIAS CONSTITUCIONAIS. MANUTENÇÃO DA SENTENÇA EM REEXAME NECESSÁRIO, COM O AJUSTE PARA CONDENAR O MUNICÍPIO AO PAGAMENTO DA TAXA JUDICIÁRIA. (TJRJ, 2016, 00027082120158190025)

SAÚDE. MEDICAMENTOS PARA TRATAMENTO INDIVIDUAL DE PACIENTE HIPOSSUFICIENTE. DEVER DE FORNECIMENTO PELO PODER PÚBLICO - MUNICÍPIO (ART. 196, CF/88) Mandado de segurança Liminar deferida Sentença concessiva Latente o direito líquido e certo da impetrante - Em decisão monocrática, nega-se seguimento ao reexame necessário e ao recurso da Fazenda Pública. (TJSP, 2014, APL: 00144586720138260066)

MANDADO DE SEGURANÇA - PATOLOGIA - ESTENOSE DE LARINGE COM DISFUNÇÃO DA FONAÇÃO E DA RESPIRAÇÃO PROCEDIMENTO - NEGATIVA DO PODER PÚBLICO MUNICIPAL CIRURGIA DE LARINGE - EQUIPAMENTO ESPECÍFICO - LASER DE DIODO - IMPRESCINDIBILIDADE - LAUDO MÉDICO - PACIENTE ADOLESCENTE - DIGNIDADE DA PESSOA HUMANA - DIREITO À VIDA E À SAÚDE - PREVISÃO CONSTITUCIONAL - ÔNUS DO ESTADO - INTELIGÊNCIA DO ART. 196 DA CF - DIREITO LÍQUIDO E CERTO CONCESSÃO DA SEGURANÇA. Demonstrada a imprescindibilidade do ato cirúrgico prescrito para tratamento da impetrante, é imperioso o fornecimento de equipamentos específicos pelo Impetrado. Insere-se no âmbito da garantia do direito à saúde e a dignidade da pessoa, exigir-se de ente público da federação que arque com a concessão de equipamento próprio, cujo fim é indispensável para o tratamento da Estenose de Laringe, visando melhorar a qualidade de sua saúde e garantir o seu mínimo bem-estar à impetrante. (TJPB, 2015, MS: 20076205020148150000 2007620-50.2014.815.0000)

Referindo-se as ações que têm deferido pedido de tutela em caráter de urgência, sob pena de uma multa diária, quando proposta contra o Município e mais um Ente da federação, na grande maioria das vezes, coloca-o em situação de desvantagem, haja vista que até que seja cumprida a intimação e viabilize o cumprimento das diligências cabíveis para os Entes de segunda e terceira escala - Estados Membros e União, os Municípios que são intimados mais agilmente, ficam obrigados a dar cumprimento à ordem judicial na mesma toada.

Além da análise genérica dos pedidos envolvendo o direito à saúde, ao ajustar uma pena de multa, os magistrados também não são específicos em estremar os limites das responsabilidades pelas astreintes em caso de eventual descumprimento, violando regras processuais contidas nos artigos 536, 537 e 805, todos do Novo Código Processual Civil. ${ }^{11}$

\footnotetext{
${ }^{11}$ Art. 536. No cumprimento de sentença que reconheça a exigibilidade de obrigação de fazer ou de não fazer, o juiz poderá, de ofício ou a requerimento, para a efetivação da tutela específica ou a obtenção de tutela pelo resultado prático equivalente, determinar as medidas necessárias à satisfação do exequente.

$\S 1^{\underline{o}}$ Para atender ao disposto no caput, o juiz poderá determinar, entre outras medidas, a imposição de multa, a busca e apreensão, a remoção de pessoas e coisas, o desfazimento de obras e o impedimento de atividade nociva, podendo, caso necessário, requisitar o auxílio de força policial.
}

Revista de Direito Brasileira | São Paulo, SP | v. 20 | n. 8 | p. 174-191 |Mai./Ago. 2018 
AGRAVO DE INSTRUMENTO. DIREITO À SAÚDE. OBRIGAÇÃO DE FAZER. TRATAMENTO FORA DO DOMICÍLIO. DIREITO FUNDAMENTAL E SOCIAL. FIXAÇÃO DE ASTREINTES CONTRA A FAZENDA PÚBLICA. POSSIBILIDADE. VALOR DA MULTA. REDUÇÃO. PRAZO PARA CUMPRIMENTO DA OBRIGAÇÃO. DILAÇÃO. RECURSO PARCIALMENTE PROVIDO. [...] Diante da probabilidade do direito e do perigo da demora, correta a decisão agravada ao deferir a tutela em favor da agravada e determinar aos entespúblicosmunicipal e estadual que viabilizem o encaminhamento desta para tratamento fora de domicílio - TFD; O direito à saúde é um direito fundamental social do indivíduo, de modo que compete à União, aos Estados e aos Municípios, solidariamente, fornecer tratamento médico aos que dele necessitam; Não há que se falar em desarazoabilidade quanto à aplicação de medida coercitiva para o caso de descumprimento da obrigação de fazer, na medida em que esta se mostra cabível, por causar mais temor à Fazenda Pública, impulsionando-a a assumir um comportamento tendente à satisfação da obrigação imposta; [...] Recurso parcialmente provido, para reduzir o valor da multa diária ao patamar de $\mathrm{R} \$ 500,00$ e fixar o prazo de 40 dias para cumprimento da decisão de primeiro grau, considerando que se trata de procedimento de alta complexidade que depende da CNRAC.(TJAC, 2017, AI: 10018752820168010000 AC 1001875-28.2016.8.01.0000)

A multa diária, fixada como medida coercitiva, para o caso de desobediência da determinação judicial abarcando o direito à saúde, atinge o Ente municipal de forma tangente tanto quando processado isoladamente e não sendo este o responsável direto - definido nos limites das políticas públicas - quanto quando compõe o polo passivo em litisconsorte com outro (s) Ente (s) e é intimado primeiramente, ficando obrigado a dispor de recursos públicos,

$\S 2^{\underline{0}} \mathrm{O}$ mandado de busca e apreensão de pessoas e coisas será cumprido por 2 (dois) oficiais de justiça, observandose o disposto no art. $846, \S \S 1_{-}^{\circ}$ a $4^{\circ}$, se houver necessidade de arrombamento.

$\S 3^{\circ} \mathrm{O}$ executado incidirá nas penas de litigância de má-fé quando injustificadamente descumprir a ordem judicial, sem prejuízo de sua responsabilização por crime de desobediência.

$\S 4^{0}$ No cumprimento de sentença que reconheça a exigibilidade de obrigação de fazer ou de não fazer, aplica-se o art. 525, no que couber.

$\S 5^{\circ} \mathrm{O}$ disposto neste artigo aplica-se, no que couber, ao cumprimento de sentença que reconheça deveres de fazer e de não fazer de natureza não obrigacional.

Art. 537. A multa independe de requerimento da parte e poderá ser aplicada na fase de conhecimento, em tutela provisória ou na sentença, ou na fase de execução, desde que seja suficiente e compatível com a obrigação e que se determine prazo razoável para cumprimento do preceito.

$\S 1^{\circ} \mathrm{O}$ juiz poderá, de ofício ou a requerimento, modificar o valor ou a periodicidade da multa vincenda ou excluí-la, caso verifique que:

I - se tornou insuficiente ou excessiva;

II - o obrigado demonstrou cumprimento parcial superveniente da obrigação ou justa causa para o descumprimento.

$\S 2^{\underline{O}} \mathrm{O}$ valor da multa será devido ao exequente.

§ 3- A decisão que fixa a multa é passível de cumprimento provisório, devendo ser depositada em juízo, permitido o levantamento do valor após o trânsito em julgado da sentença favorável à parte.

$\S 4^{\circ}$ A multa será devida desde o dia em que se configurar o descumprimento da decisão e incidirá enquanto não for cumprida a decisão que a tiver cominado.

$\S 5^{\mathrm{o}} \mathrm{O}$ disposto neste artigo aplica-se, no que couber, ao cumprimento de sentença que reconheça deveres de fazer e de não fazer de natureza não obrigacional.

$[\ldots]$

Art. 805. Quando por vários meios o exequente puder promover a execução, o juiz mandará que se faça pelo modo menos gravoso para o executado.

Parágrafo único. Ao executado que alegar ser a medida executiva mais gravosa incumbe indicar outros meios mais eficazes e menos onerosos, sob pena de manutenção dos atos executivos já determinados. 
comprometendo rubricas orçamentárias e a esfera própria da coletividade assistida pelo demandado.

Os impactos da judicialização do direito à saúde em desfavor dos municípios são diversos, evidenciando perigo de dano irreparável ou de difícil reparação a ordem pública, justificando daí a relevância da observância do conjunto de normas que regulam a matéria e consequentemente da fundamentação das decisões que deliberam ações desta natureza. (OLIVEIRA; COSTA, 2015, p. 86)

Com vistas a impedir lesão dessa natureza, recentemente o presidente do Tribunal de Justiça de São Paulo, Dr. José Renato Nalini, suspendeu as decisões de antecipação de tutela para o fornecimento da fosfoetanolamina sintética para 368 demandantes, por não considerar a substância um medicamento e não estar a droga regularmente apta para ser comercializada, tratando-se meramente de um experimento laboratorial da Universidade de São Paulo. (TJSP,2015, SL: 21949626720158260000 SP 2194962-67.2015.8.26.0000)

O fenômeno da judicialização trata-se de tema complexo, envolvendo questões legais, éticas, políticas, econômicas e sociais, questionando o papel do Estado, a distribuição dos recursos e as relações entre direitos individuais e coletivos e, portanto, deveria ser utilizado como medida de exceção e não como regra. Contudo, ante as decisões genéricas que vêm sendo exaradas, sem a observância devida aos direitos sociais como um todo, atentando-se para a questão de que visam atenuar as desigualdades fáticas existentes na sociedade, garantindo o acesso igualitário à saúde, os particulares tem-se valido cada vez mais de tal recursos para buscarem a todo custo a garantia individual do direito à saúde.

O fato é que a constitucionalização dos direitos sociais - dentre eles a saúde - e os problemas do Estado em aprovisionar efetivamente tais serviços, contribuíram sobremaneira para o atual estágio de desenvolvimento do fenômeno da judicialização em território nacional; porém a concretização eficaz do direito à saúde carece que seja levada em consideração a observância da ordem principiológica presente no Direito, não sendo função do magistrado obrigar que determinado Ente estatal socorra direitos subjetivos com o custo de medicamentos e/ou procedimentos que não estejam previamente selecionados por critérios técnicos, indicando as necessidades mais iminentes da população e os limites de responsabilidade estabelecidos para cada Ente federado. (TJMG, 2008, TJ-MG 100000745630160001 MG 1.0000.07.456301-6/000 1)

A dificuldade maior imposta aos municípios pelo fenômeno da judicialização do direito à saúde está exatamente em daraplicação indistintapara este direito em prol daqueles que buscam o judiciário, pautados fundamentalmente no artigo 196 da Carta Magna. Tais decisões ultrapassamvários limites, que dentre eles, elegeu o trabalho como contrassenso para o todo social: os princípios da isonomia e da reserva do possível, discussão esta que será adiante ponderada.

\section{O DIREITO À SAÚDE E OS PRINCÍPIOS JURÍDICOS DA ISONOMIA E DA RESERVA DO POSSÍVEL}

Quando uma pesquisa remete ao tema "princípios", é certo que sempre haverá algum ponto conveniente a ser explorado, considerando-se os formatos como são desenvolvidos no ordenamento jurídico - implícitos e expressos, de forma que não é possível eleger uma preeminência principiológica, exceto no tocante ao princípio da certeza do direito, cujo desígnio é garantir o convívio social sistematizado. (NICOLAU JÚNIOR, 2004, n.p.)

Paulo de Barros Carvalho venerando o assunto, afirma tratar-se de linhas diretivas que cientificam e clareiam a concepção de segmentos normativos, destinando-lhes característica de elemento limitado e auxiliando para a inclusão de um fascículo de normas. (CARVALHO, 1991, p. 90) José Joaquim Gomes Canotilho defende como sendo princípios jurídicos fundamentais, 
aqueles historicamente considerados e paulatinamente inseridos na compreensão jurídica, como uma afeição propagada ou tácita na Carta Constitucional. (CANOTILHO, 2002, p. 1.148)

Numa visão condensada sobre o assunto, Hugo de Brito Machado diz que os princípios jurídicos podem ser ditados normas jurídicas distintas das demais pelo valor que apresentam ao sistema jurídico, considerando-os a própria estrutura deste sistema, funcionando como vetores. (MACHADO, 2004, p. 31)

Nestes termos, edificar um direito constitucionalmente garantido, no caso específico da pesquisa o direito à saúde, sem considerar a relevância de um ou mais princípios jurídicos cabíveis no contexto, pode suscitar a ruína irrestrita do sistema jurídico, enquanto que o objetivo deveria ser o inverso - a sua sustentação e o seu desenvolvimento.

Os resultados provenientes do fenômeno da judicialização do direito à saúde em detrimento dos Municípios, garantindo aos particulares a tutela sobre fármacos que extrapolam a competência municipal têm surgido como grande contrassenso aos princípios da isonomia e da reserva do possível como se destacará adiante.

\subsection{PRINCÍPIO DA IGUALDADE}

Em território brasileiro, a definição mais célere para o princípio da igualdade ou da isonomia é proveniente do discurso de Rui Barbosa dedicado aos formandos da Faculdade de Direito do Largo de São Francisco, intitulado Oração aos Moços no ano de 1920, destacando-se que: "A regra da igualdade não consiste senão em aquinhoar desigualmente aos desiguais, na medida em que se desigualam. [...] Tratar com desigualdade a iguais, ou a desiguais com igualdade, seria desigualdade flagrante, e não igualdade real”. (BARBOSA, 1997, p. 26)

No sentido substancial, a isonomia significa a dedicação de tratamento igualitário a todos os indivíduos, dedicando-lhes idênticas condições de acesso aos bens da vida humana. Já no sentido formal, é verificado imediatamente na direção especificada na norma e mediatamente aos que devem aplica-la.

Celso Antônio Bandeira de Mello na obra "O conteúdo jurídico do princípio da igualdade" elucidou as situações que a lei pode fundar discriminações, apontando o inverso também, ou seja, as que o discrímen legal aponta para a colisão com a isonomia. Referindo as discriminações, o autor admite como possível quando é identificada uma similitude lógica entre o discrímen legal e o desnível derivado, desde que, para tanto, o resultado esteja em conformidade aos interesses tracejados no Texto Constitucional. Arrematando o raciocínio, Celso Antônio Bandeira de Mello diz que para não haver agressão do princípio da isonomia é necessária a consagração de quatro elementos: a) que não atinja de forma absoluta apenas um indivíduo; b) que a desequiparação de situações e/ou pessoas derive de núcleos distintos - com particularidades diferenciadas; c) inabstractus, que se verifique a existência de conexão entre os fatos existentes distintos e a diferenciação definida pela norma jurídica em função deles; d) e por derradeiro, in concreto, que o vínculo de relação, seja conexo para o desempenho dos interesses constitucionalmente garantidos, isto é, dê como resultado a razão valiosa do cerne da Carta Magna - a proteção do bem do público. (MELLO, 1999, p. 41)

Nesse passo, o protagonismo do Poder judiciário na tutela do direito à saúde, atuando para dar efetividade irrestrita e absoluta ao direito constitucional em tela, incide na desconsideração de toda conjectura da definição do princípio da isonomia. Logo, nos casos em que o Ente municipal for compelido a entregar um fármaco e/ou arcar com um procedimento clínico que não esteja definido dentro das políticas públicas como de sua competência, terá que dispor de parcela do seu orçamento para arcar com despesa que não tinha previsão para tanto (já despontando aqui contrassenso com o princípio da reserva do possível, doravante explicado), comprometendo a eficácia no atendimento da coletividade - como devido. Veja-se que os demais munícipes são preteridos, uma vez que a decisão judicial atingindo especificamente o particular 
(demandante) deve ser atendida, uma vez que o descumprimento da medida pelo município pode implicar uma penalidade pecuniária - as astreintes.

\subsection{PRINCÍPIO DA RESERVA DO POSSÍVEL}

Uma construção da doutrina alemã, considerando o fato que as rubricas orçamentárias estatais são finitas e o rol de direitos sociais e fundamentais parece ser meramente exemplificativo, não tendo um fim em si mesmo, o princípio da reserva do possível surgiu no sistema jurídico para resolver um problema sócio-jurídico manifesto, oriundo da impossibilidade do Estado conseguir atuar para a efetivação irrestrita de todos os direitos, que em tese deveriam ser garantidos à universalidade. (KRELL, 2002, p. 52)

Tal princípio, para tanto, esbarra na interpretação constitucional acentuada, que é realizada no sentido de julgar no que equivaleria à escusa do Estado em dar efetividade aos direitos e garantias fundamentais, como lhe é imposto pela norma por dever. E foi neste contexto, que primando harmonizar as duas defesas - da impossibilidade de recursos e do dever ideal e absoluto da tutela estatal, que a doutrina cunhou a caução do núcleo essencial (o mínimo existencial), primando relativizar a definição do princípio da reserva do possível, o que, contudo, só pode ser afeiçoado a partir da avaliação do binômio necessidade-capacidade, ou seja, deve-se levar em consideração não apenas o sujeito que busca a satisfação das suas necessidades, mas igualmente o provedor destas. (SILVA, 2015, p. 29)

Referenciando o princípio da reserva do possível, Gilmar Ferreira Mendes ponderou que embora as decisões judiciais estejam conectadas juridicamente, o fato é que para a execução destas, dentre outras condicionantes, está refreada à reserva do financeiramente possível (Vorbehalt des finanziell Möglichen). (MENDES, 2002, p. 7) Logo, a efetivação dos direitos sociais e fundamentais, está na verdade condicionada às possibilidades reais do Estado em poder garantir, limitadas a previsão orçamentária.

Neste sentido, destaca-se que a própria Carta da República apresentou no texto a vedação do início de programas ou projetos não incluídos na lei orçamentária anual (artigo 167, inciso I), a realização de despesas que excedam os créditos orçamentários (artigo 167, inciso II) e a transposição, o remanejamento ou a transferência de recursos de uma categoria de programação para outra ou de um órgão para outro, sem prévia autorização legislativa (artigo 167, inciso VI).

Foi fulgente a preocupação do constituinte quanto à delimitação da previsão das despesas do poder público, não cabendo ao magistrado o domínio jurídico de corromper esta regra constitucional e estender a obrigação estatal - limitada no alcance da previsão orçamentária, (MOURA; RIBEIRO, 2017, p. 236) pautando seu julgamento isolada e despreocupadamente na interpretação do artigo 196 da Lei Maior, sem considerar os limites e a competência de cada Ente federado.

Os resultados do fenômeno da judicialização do direito à saúde têm evidenciado um paradoxo para os municípios no que atine o princípio da reserva do possível (limitação material do Município) e como não pode estar dissociado domínimo existencial (demandas sociais infindáveis), que na concepção do ministro José Celso de Mello Filho deve ser resolvidopela presença cumulativa de dois elementos: a razoabilidade da pretensão individual/social deduzida em face do Poder Público e a existência de disponibilidade financeira do Poder Público para tornar efetivas as prestações estatais positivas concretizadoras de tais prerrogativas individuais e/ou coletivas dele reclamadas. (STF, Informativo n. ${ }^{\circ}$ 345/2004, n.p.)

No âmbito do direito à saúde, a responsabilidade real e que deve ser atribuída e exigida dos entes municipais, limita-se aos medicamentos que integram a denominada farmácia básica composta pelas políticas públicas do SUS, cujo alcance encontra-se devidamente previsto nas rubricas orçamentárias municipais e por tal razão, sem dificultar o cumprimento de outro mandamento constitucional: a garantia do acesso universal e igualitário à saúde. 
Destarte, para o tema proposto a discussão é de especial importância analisar a temática da judicialização de políticas públicas e a efetivação de direitos fundamentais e sociais, que não obstante, carece ser ponderado que a vinculação de uma decisão judicial que determine o dispêndio do orçamento público para a concretização de um direito social à um indivíduo, deveras coloca uma gama de outros direitos fundamentais em risco para o todo coletivo, vez que deve ser ponderada a efetividade dos direitossociais e os efeitos dos gastos regressivos no alcance dos direitos fundamentais e no papel que deve exercer o orçamento na promoção dos direitos sociais para o coletivo e a suacorrelação com reserva do possível.

\section{CONCLUSÃO}

A par do que foi discutido no presente artigo, observou-se que o fenômeno da judicialização do direito à saúde - tema demasiadamente complexo, envolvendo questões legais, éticas, políticas, econômicas e sociais - vem proporcionando discrepâncias de valores sociais no tocante ao contrassenso gerado em relação aos princípios da isonomia e da reserva do possível. Isso levando-se em consideração a forma como tem se desenvolvido por meio de decisões genéricas exaradas num contexto simples demais na prática, que têm deferido o direito à saúde a qualquer custo, contra qualquer Ente federado, sem o juízo de valor essencial para averiguar o alcance de responsabilidade e a competência de cada qual.

A presente pesquisa elegeu as consequências sofridas pelos Municípios, maiores prejudicados nos processos de judicialização do direito à saúde, por comporem o polo passivo de quase a totalidade das demandas desta natureza e ainda, por força da intimação mais ágil em desfavor dos Entes municipais, que ficam obrigados a cumprirem a medida imposta de forma célere.

O fato da saúde ser abalizada pelo Texto Constitucional como um direito universal de todos e um dever do Estado, não faz dela um direito absoluto, isso em razão de que a interpretação isolada da norma contida no artigo de 196 da Constituição da República, por si só, deve ser considerada ineficiente, por suscitar uma gama infindável de problemas sócio-jurídicos não só para os cidadãos como para o próprio Estado.

Uma vez esclarecido que o direito à saúde não está adstrito ao ora previsto no artigo 196 da Lei Maior, o trabalho demonstrou que muitas são as diretrizes constitucionais e extraconstitucionais que tratam transversalmente do assunto, ponderando que este não deve ser desenvolvido apenas no campo da liberdade individual, carecendo desenvolver-se equitativamente com igualdade social, respeitando-se os limites orçamentários da administração pública.

Nestes termos, o intuito dessa pesquisa foi chamar a atenção para a ineficiência da garantia do direito constitucional à saúde decorrente dos riscos suscitados pelo fenômeno da judicialização deste direito em desfavor dos municípios, por estarem motivando tamanha incoerência no seu desenvolvimento pelo protagonismo judiciário à ordem constitucional, especialmente no tocante aos princípios da isonomia - decisões atingindo apenas particulares/demandantes em detrimento da coletividade; e da reserva do possível - sem o zelo de atenção quanto aos limites orçamentários dos Entes municipais para cobrir a obrigação demandada em desfavor.

Altercando ainda o trabalho sobre a necessidade, diante um caso concreto, do poder judiciário proceder com a máxima do cuidado de uma leitura substancial de todas as normas e princípios que circundam a matéria, considerando a divisão do grau de responsabilidade de cada Ente da federação, bem como a competência para prestar tal garantia do fármaco e/ou procedimento médico demandado. 


\section{REFERÊNCIAS}

BARBOSA, Rui. Oração aos moços. Edição popular anotada por Adriano da Gama Kury. 5. ed. Rio de Janeiro: Fundação Casa de Rui Barbosa, 1997.

BRASIL. Constituição da República Federativa do Brasil de 1988. Disponível em: <http://www.planalto.gov.br/ccivil_03/constituicao/constituicaocompilado.htm>. Acesso em 21 mar. 2017.

Decreto $n^{\circ}$ 7.508, de 28 de junho de 2011: regulamenta a Lei no 8.080, de 19 de setembro de 1990, para dispor sobre a organização do Sistema Único de Saúde - SUS, o planejamento da saúde, a assistência à saúde e a articulação interfederativa, e dá outras providências. Disponível em: <http://www.planalto.gov.br/ccivil_03/_ato20112014/2011/decreto/d7508.htm>. Acesso em 21 mar. 2017.

Entenda $\quad$ SUS. Disponível em:<http://portalsaude.saude.gov.br/index.php/cidadao/entenda-o-sus>. Acesso em 21 mar. 2017.

Lei $n^{\circ}$ 8.080, de 19 de setembro de 1990: dispõe sobre as condições para a promoção, proteção e recuperação da saúde, a organização e o funcionamento dos serviços correspondentes e dá outras providências. Disponível em: <http://www.planalto.gov.br/ccivil_03/leis/L8080.htm>. Acesso em 21 mar. 2017.

Portaria n 2.982 de 26 de novembro de 2009: aprova as normas de execução e de financiamento da Assistência Farmacêutica na Atenção Básica. Disponível em: <http://bvsms.saude.gov.br/bvs/saudelegis/gm/2009/prt2982_26_11_2009_rep.html>. Acesso em 21 mar. 2017.

CANOTILHO, José Joaquim Gomes. Direito constitucional e teoria da constituição. 5. ed. Coimbra: Almedina, 2002.

CARVALHO, Paulo de Barros. Curso de direito tributário. 4. ed. São Paulo: Saraiva, 1991.

FRANÇA, Genival Veloso. Direito médico. 10. ed. Rio de Janeiro: Forense, 2010.

GUERRA, Luis López; LUQUE, Luis Aguiar de. Las constituciones de iberoamerica (II). Centro de estudios políticos y constitucionales: Madrid, 2009.

HOUAISS, Antônio; VILLAR, Mauro de Salles. Dicionário Houaiss da língua portuguesa. Rio de Janeiro: Objetiva, 2001.

KELSEN, Hans. Teoria pura do direito. Tradução de João Baptista Machado. 6. ed. São Paulo: Martins Fontes, 1998.

KRELL, Andreas Joachim. Direitos sociais e controle judicial no Brasil e na Alemanha: os (des) caminhos de um direito constitucional "comparado". Porto Alegre: Fabris Editor, 2002.

MACHADO, Hugo de Brito. Os princípios jurídicos da tributação na constituição de 1988. 5. Ed. São Paulo: RT, 2004. 
MELlO, Celso Antônio Bandeira de. Conteúdo jurídico do princípio da igualdade. 3. ed. São Paulo: Malheiros, 1999.

MENDES, Gilmar Ferreira. Os direitos fundamentais e seus múltiplos significados na ordem constitucional. Revista Diálogo Jurídico. No 10, jan de 2002, Salvador. Disponível em: <http://georgemlima.xpg.uol.com.br/mendes.pdf >. Acesso em 24 mar. 2017.

MOURA, Emerson Affonso da Costa; RIBEIRO, Jamir Calili. Direitos fundamentais sociais, orçamento público e reserva do possível: o dever de progressividade nos gastos públicos. Revista de Direito Brasileira. São Paulo, SP, v. 16, n. 7, p. 225-241, Jan./Abr. 2017. Disponível em: <http://www.rdb.org.br/ojs/index.php/rdb/article/view/510/330>. Acesso em 14 out. 2017.

NICOLAU JÚNIOR, Mauro. Segurança jurídica e certeza do direito: realidade ou utopia num Estado democrático de direito? Universo Jurídico, Ano XI, Juiz de Fora, 14 Out. 2004. Disponível em: <http://uj.novaprolink.com.br/doutrina/1868/seguranca_juridica_e_certeza_do_direito_realidade_ ou_utopia_num_estado_democratico_de_direito>. Acesso em 24 mar. 2017.

OLIVEIRA, Kátia Cristine Santos de; COSTA, Jamille Coutinho. Direito à saúde: da (in)efetividade das políticas públicas à sua judicialização como forma de garantir o mínimo existencial. Revista de Direito Brasileira. v. 1, n. 1 (2011). Disponível em: <http://www.rdb.org.br/ojs/index.php/rdb/article/view/53/52>. Acesso em 14 out. 2017.

REALE, Miguel. Lições preliminares de direito. 22. ed. São Paulo: Saraiva, 1995.

SÃO PAULO, Folha de. Entenda a judicialização da saúde e debate do STF sobre acesso a remédios. Disponível em: <http://www1.folha.uol.com.br/cotidiano/2016/09/1817519-entenda-ajudicializacao-da-saude-e-debate-do-stf-sobre-acesso-a-remedios.shtml>. Acesso em 21 mar. 2017.

SILVA, Leny Pereira da Silva. Direito à saúde e o princípio da reserva do possível. 2015. 64 f. Monografia (pós-graduação) - Instituto Brasiliense de Direito Público. Brasília: IDP, 2015. Disponível

em: $<$ http://www.stf.jus.br/arquivo/cms/processoAudienciaPublicaSaude/anexo/DIREITO_A_SAUD E_por_Leny.pdf >. Acesso em: 22 mar. 2017.

STF. Informativo n. ${ }^{\circ}$ 345. ADPF45 MC/DF: Políticas Públicas - Intervenção Judicial - "Reserva do Possível" (Transcrições). Disponível em: <http://www.stf.jus.br/arquivo/informativo/documento/informativo345.htm>. Acesso em: 25 mar. 2017.

TEALDI, Juan Carlos (Dir.). Diccionario latinoamericano de bioética. Bogotá: UNESCO - Red Latinoamericana y del Caribe de Bioética: Universidad Nacional de Colombia, 2008.

TJMG, Tribunal de Justiça do Estado de Minas Gerais. TJ-MG 100000745630160001 MG 1.0000.07.456301-6/000(1). Relator: Dárcio Lopardi Mendes, Data de Julgamento: 07/11/2007, Data de Publicação: 29/02/2008. 
TJAC, Tribunal de Justiça do Estado do Acre. AI: 10018752820168010000 AC 100187528.2016.8.01.0000. Relator: Des. Roberto Barros, Data de Julgamento: 24/04/2017, Segunda Câmara Cível, Data de Publicação: 26/04/2017.

TJAL, Tribunal de Justiça do Estado de Alagoas. APL: 00621685820108020001 AL 006216858.2010.8.02.0001. Relator: Des. Paulo Barros da Silva Lima, Data de Julgamento: 06/11/2014, $2^{a}$ Câmara Cível, Data de Publicação: 11/11/2014.

TJPB, Tribunal de Justiça do Estado da Paraíba. MS: 200762050201481500002007620 50.2014.815.0000. Relator: DESA MARIA DE FATIMA MORAES B CAVALCANTI, Data de Julgamento: 09/12/2015, 1. SECAO.

TJRJ, Tribunal de Justiça do Estado do Rio de Janeiro. Remessa necessária: 00027082120158190025. Rio de Janeiro, Itaocara, Vara Única, Relator: Cesar Felipe Cury, Data de Julgamento: 14/12/2016, Décima Primeira Câmara Cível, Data de Publicação: 19/12/2016.

TJRS, Tribunal de Justiça do Estado do Rio Grande do Sul. AI: 70052460383 RS. Relator: João Barcelos de Souza Junior, Data de Julgamento: 27/03/2013, Segunda Câmara Cível, Data de Publicação: Diário da Justiça do dia 12/04/2013.

TJSP, Tribunal de Justiça do Estado de São Paulo. APL: 00144586720138260066 SP 0014458 67.2013.8.26.0066. Relator: Ponte Neto, Data de Julgamento: 03/09/2014, $8^{a}$ Câmara de Direito Público, Data de Publicação: 04/09/2014.

SL: 21949626720158260000 SP 2194962-67.2015.8.26.0000. Relator: José Renato Nalini, Data de Julgamento: 18/09/2015, Presidência, Data de Publicação: 19/09/2015. 